WellBeing International

WBI Studies Repository

7-2009

\title{
Fallow Bucks Get Hoarse: Vocal Fatigue as a Possible Signal to Conspecifics
}

\author{
Elisabetta Vannoni \\ University of Zurich \\ Alan G. McElligott \\ University of Zurich
}

Follow this and additional works at: https://www.wellbeingintlstudiesrepository.org/acwp_vsm

Part of the Animal Structures Commons, Animal Studies Commons, and the Other Animal Sciences Commons

\section{Recommended Citation}

Vannoni, E., \& McElligott, A. G. (2009). Fallow bucks get hoarse: vocal fatigue as a possible signal to conspecifics. Animal Behaviour, 78(1), 3-10.

This material is brought to you for free and open access by WellBeing International. It has been accepted for inclusion by an authorized administrator of the WBI Studies Repository. For more information, please contact wbisr-info@wellbeingintl.org.

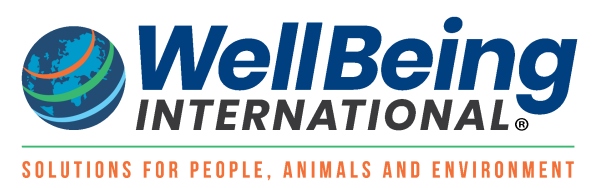




\title{
Fallow Bucks Get Hoarse: Vocal Fatigue as a Possible Signal to Conspecifics
}

\author{
Elisabetta Vannoni and Alan G. McElligott \\ University of Zürich
}

\section{$\underline{\text { KEYWORDS }}$}

animal communication, bioacoustics, Dama dama, fallow deer, fatigue, male quality, mating, sexual selection, signal, vocalization

\begin{abstract}
Many studies of sexually selected vocal communication assume that calls remain stable throughout the breeding season. However, during this period, physiological and social factors change and these can have strong effects on the structure of calls and calling rates. During the rut, fallow bucks, Dama dama, reduce their feeding and increase the time and energy spent on vocalizing and fighting to gain matings, and consequently their body condition declines greatly. The availability of matings and intensity of competition between males also change. Therefore, we predicted that male vocal signalling would vary over time in response to the changing intersexual and intrasexual selective environment. We measured the structure of fallow buck groans and the groaning rate throughout the rut. Fundamental frequencyrelated parameters were highest at the beginning and at the end of the rut, and lowest during the middle when most matings occur. The fundamental frequency perturbation along the groan (Jitter) remained stable throughout the rut, whereas the number of pulses and duration of the groans decreased linearly. The minimum formant dispersion did not vary significantly over the rut. Groaning rate increased towards the middle of the rut and then rapidly decreased afterwards. We suggest that changes in the structure of groans and groaning rate are associated with the declining body condition of males and variation in the availability of mating opportunities. The breakdown in some aspects of call structure towards the end of the breeding season may represent an honest signal that could be widespread in other species.
\end{abstract}

Recent research on mammal vocal communication has focused on determining the functions of calls by elucidating the information they convey to receivers (Fischer et al. 2002; Torriani et al. 2006; Pfefferle et al. 2007; Theis et al. 2007). The information transmitted through vocalizations can be encoded in different aspects of a call, such as the acoustic structure and calling rate (Clutton-Brock \& Albon 1979; McComb 1991; McElligott \& Hayden 1999; Fischer et al. 2004). These vocal features may be affected by both 
social and physiological factors and therefore vary over both short and longer timescales (Koren \& Geffen 2009).

Social context-related changes in the acoustic structure of calls generally reflect changes in arousal or motivation of an animal (Elowson \& Snowdon 1994; Mitani \& Brandt 1994; McElligott \& Hayden 1999; Rukstalis et al. 2003). Intensity of arousal might be communicated in vocal signals by altered patterns of calling in space and time and/or by changes in the acoustic parameters of calls (Fichtel \& Hammerschmidt 2002; Fischer et al. 2002; Bachorowski \& Owren 2003). For example, adult male baboons, Papio cynocephalus ursinus, produce the 'wahoo' call at far greater rates during aggressive contests than comparatively low-arousal circumstances and the acoustic structure of these vocalizations changes following protracted calling (Fischer et al. 2002, 2004). Prolonged calling associated with high physical activity has been shown to alter both the frequencies of calls and the calling rate (Liénard \& Di Benedetto 1999; Fischer et al. 2004).

Mechanisms at the basis of the different motivational states of the caller may contribute to the contextdependent acoustic modifications (Morton 1977, 1982). Short-term variation in the arousal state may alter respiration and therefore vocal production (Titze 1994; Scherer 2003). Moreover, fluctuations in hormone levels occurring during social interactions may influence both anatomical and neurophysiological structures involved in the production of vocal signals and therefore result in modified acoustic patterns (Rolf \& Fischer 1990; Dabbs \& Mallinger 1999; Semple \& McComb 2000; Yamaguchi \& Kelley 2002; Manteuffel et al. 2004).

To understand the evolution of any vocal signal, it is important to explore the source of its variation by investigating short-term changes in both the acoustic structure of calls and other aspects of vocal behaviour (e.g. calling rate), which might indicate different communicative functions. Modification of the acoustic structure of the call within individuals over time may have implications for individual recognition, whereas changes in the calling rate may provide information on the current motivation and condition of the caller (Jorgensen \& French 1998; Rukstalis et al. 2003; Theis et al. 2007).

The sexually selected calls produced by fallow bucks provide an excellent model for investigating shortterm vocal changes in mammals. When they become socially mature ( $>4$ years old), males do not vocalize for most of the year, and then have an extremely intense period of vocal activity during the rut. At this time they produce a repetitive and stereotypic call known as a groan (Reby et al. 1998; Vannoni \& McElligott 2007). Two types of groans can be identified: the common and the harsh groan. Harsh groans are generally only produced during intense chasing and herding behaviour, whereas common groans are given in all contexts (Vannoni \& McElligott 2007). The acoustic structure of fallow buck groans is individually distinctive and contains information on male body size and dominance status (Reby et al. 1998; McElligott et al. 2006; Vannoni \& McElligott 2007, 2008). Higher-ranked males start groaning several weeks before the first matings take place, and they maintain very high groaning rates over prolonged periods during the peak of the rut when most matings take place (McElligott \& Hayden 1999; McElligott et al. 1999). Therefore several aspects of the vocal behaviour of fallow bucks represent honest signals of male quality potentially available to other males and females.

Variation in the number of nearby competing males and oestrous females during the rut determines shortterm changes in arousal and motivation of the males and these affect their vocal behaviour (McElligott \& Hayden 1999). Furthermore, the dramatic decline in body condition that males undergo at this time (McElligott et al. 2003) may also affect both physiology and behaviour, including vocal display. Male vocal activity is generally reduced over the last days of the rut and males often appear fatigued (E. Vannoni \& A.G. McElligott, personal observation). Moreover, groans given at the end of the rut usually sound noisier and higher in pitch (fundamental frequency, F0) than those given at the beginning (Reby et al. 1998; E. 
Vannoni \& A.G. McElligott, personal observation). Changes in vocal behaviour during the rut may therefore be used as a potential source of information for competing males that may be monitoring the motivation and condition of their opponents. Fights between males differing widely in terms of dominance rank are infrequent early in the rut, but become more frequent towards the end (McElligott et al. 1998). This supports the suggestion that changes in the condition of dominant males are detectable to conspecifics. It additionally or alternatively supports the hypothesis that the threshold criteria used in the cost-benefit assessment of challenging a more dominant individual varies during the rut in response to changing availability of oestrous females. Similarly, both long-term investment in male vocal display and short-term indicators of male current condition may be used by females to evaluate prospective mates (Komers et al. 1999; McElligott et al. 1999; Farrell 2001). There is already good evidence to show that male and female deer are able to perceive relatively small changes in call structure and use them for intrasexual assessment or mate choice, respectively (Reby et al. 2005; Charlton et al. 2007a, b).

In this study, we investigated changes in the acoustic structure of common groans and groaning rate throughout the rut for the same individuals. We first measured the acoustic parameters of groans recorded at multiple time points, and then examined whether they had changed. We were therefore able to assess whether the various components of male vocal signalling would vary in response to the known changes in body condition, and the changes in the availability of oestrous females and therefore intensity of sexual selection, that occur during the rut.

\section{METHODS}

\section{Study Site and Population}

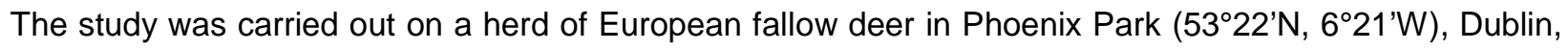
Ireland. The ages and identities of the males used in this study were known because they had been tagged as fawns, as part of routine management of the herd by the park authorities.

\section{Recording and Selection of Groans}

Recordings were made between dawn and sunset using a Sennheiser MKH70 directional microphone connected to a Sony digital audio tape recorder, DAT-TCD D100. Groans were recorded at a distance of $10-50 \mathrm{~m}$ from the vocalizing animals. We only considered common groans with low levels of background noise for analysis.

Vocalizations were imported into a computer using Avisoft-SASLab Pro 4.38 (Avisoft Bioacoustics, Berlin, Germany) at a sampling rate of $22.05 \mathrm{kHz}$ and saved in WAV format, and at 16-bit amplitude resolution (Vannoni et al. 2005; Vannoni \& McElligott 2007). Recordings were then down-sampled to $16 \mathrm{kHz}$ for a better frequency resolution. Narrow-band spectrograms of groans (FFT method, window length $=0.03 \mathrm{~s}$, time step $=1000$, frequency step $=250$, frequency resolution $=20 \mathrm{~Hz}$, Gaussian window shape, dynamic range $=35 \mathrm{~dB}$ ) were edited using Praat 4.5.01 (P. Boersma \& D. Weenink, University of Amsterdam, The Netherlands).

Recordings were carried out during three consecutive breeding seasons (2002, 2003 and 2004) between 8 October and 31 October. This period includes some days before the first matings occur (mid-October; McElligott et al. 1999), and we refer to it as the rut. We included in our analysis only males for which we had good recordings over a period of at least 6 days throughout the rut. These males were between 5 and 8 years old because this is the age range that contains the most highly vocal individuals (McElligott et al. 1999). Moreover, they had reached their asymptotic size and were not undergoing large changes associated with senescence (McElligott et al. 2002). 


\section{Sound Analysis and Phase of the Rut}

Groans are low-pitched vocalizations and are generally characterized by a pulse train structure (Fig. 1). The pulses represent the vibrations of the vocal folds, and the number of pulses divided by duration determines the fundamental frequency (F0) of the call. Although closely interrelated, we included the number of pulses, F0 and duration of calls in our detailed analyses because any or all of these variables could be perceived by conspecifics. FO can also be defined as the inverse of the interpulse interval and this can be measured as the distance between consecutive pulse onsets. Distances between pulses were measured automatically from the envelope (amplitude versus time) of the signal by using pulse train analysis in Avisoft-SASLab Pro 4.38 (Vannoni \& McElligott 2007). We calculated the values of the F0 along the groan and then averaged these values to obtain the mean $F 0$ ( $\left.F 0_{\text {mean }}\right)$. Because the fundamental frequency varies over the duration of the groan, the minimum and the maximum $\mathrm{FO}\left(\mathrm{FO}_{\min }\right.$ and $\left.\mathrm{FO}_{\max }\right)$ were also included in the analysis. From the envelope of the signal, we also calculated the number of pulses (Pulses) and the duration of the groan (Duration) as the distance between the onset of the first pulse and the end of the last one. Finally, we quantified the variation in F0 along the call using a measure of F0 perturbation, known as Jitter (Titze 1994). Jitter has been used as a measure of vocal quality in mammals (Rendall 2003) and it has been shown to vary under prolonged vocal effort in humans (Rantala et al. 1997; Laukkanen \& Kankare 2006). In this analysis, Jitter was calculated by dividing the average absolute difference between consecutive frequencies by the mean F0 per groan (peak-picking method, Horii 1979; Titze et al. 1987).

Figure 1. Narrow band spectrogram of a groan. The pulses and the first six formants are indicated on the spectrogram.

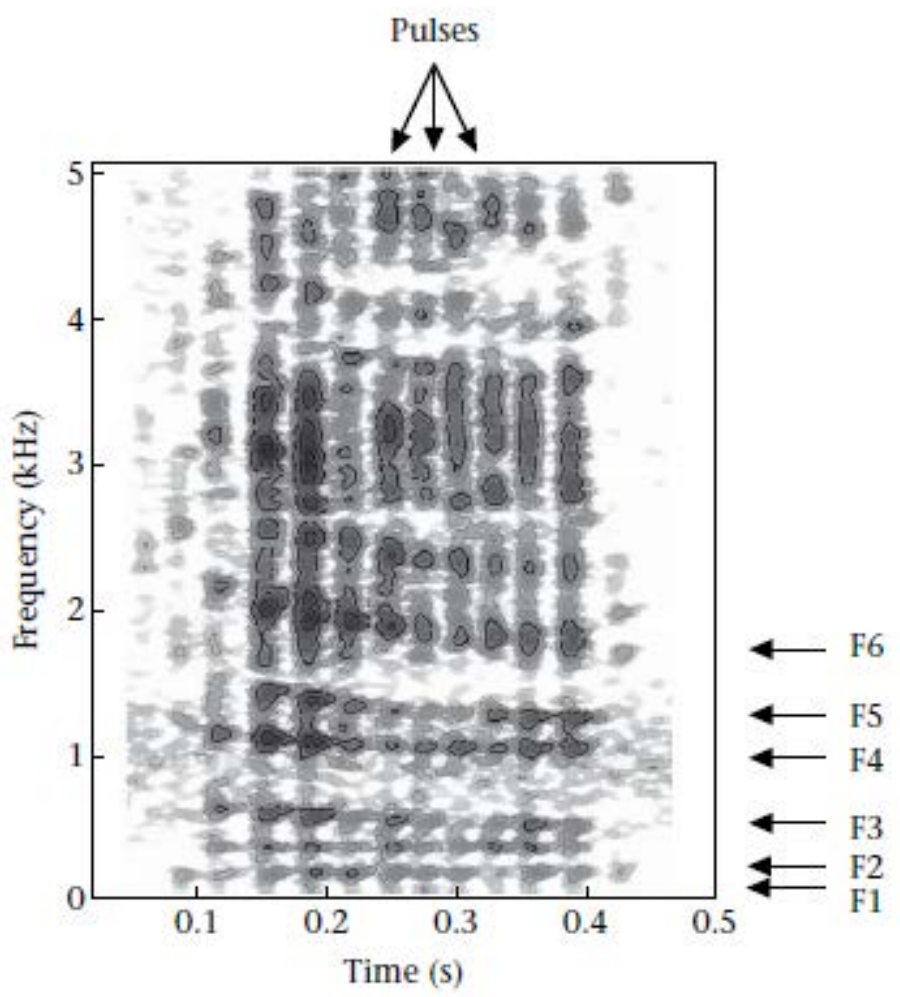

Groans contain six formants within the first $2.5 \mathrm{kHz}$ and these are evident as horizontal frequency bands in the spectrogram (F1-F6 in Fig. 1). The decreases in formant frequency along the groan represent the 
elongation of the vocal tract occurring during vocalization (McElligott et al. 2006). Formants were estimated using linear predictive coding analysis (LPC; Sound: To Formant (burg) command) in Praat 4.5.01 DSP package (Vannoni \& McElligott 2007). We calculated the minimum frequencies of the six formants $\left(F 1_{\min }-F 6_{\min }\right)$ from each groan by averaging the values over the last part of the call when formants become flat. This is the time when the larynx is pulled down to the maximum extent (McElligott et al. 2006). From the values of the minimum formant frequencies, we estimated the minimum spacing of the formants (known as minimum formant dispersion, $\mathrm{Df}_{\text {min }}$; Reby \& McComb 2003). Only this last parameter was included in the statistical analysis as it has been shown to vary with increasing motivation in deer (Reby et al. 2005).

Table 1. Number of males and groans $(\bar{X} \pm S E)$ analysed for each day of the rut

\begin{tabular}{|c|c|c|c|c|}
\hline \multirow[t]{2}{*}{ Date (October) } & \multicolumn{2}{|c|}{ F0-related and temporal parameters } & \multicolumn{2}{|c|}{ Formant dispersion } \\
\hline & Males & Groans & Males & Groans \\
\hline 8 & --- & --- & 1 & 5.0 \\
\hline 9 & 3 & $10.7 \pm 2.4$ & 2 & $5.5 \pm 0.5$ \\
\hline 10 & 1 & 5.0 & 2 & $5.0 \pm 0.0$ \\
\hline 11 & 3 & $10.7 \pm 1.8$ & 3 & $8.0 \pm 1.0$ \\
\hline 12 & 2 & $5.0 \pm 0.0$ & 3 & $8.0 \pm 1.7$ \\
\hline 13 & 1 & 13 & 1 & 10.0 \\
\hline 14 & 3 & $9.3 \pm 2.6$ & --- & --- \\
\hline 15 & 5 & $5.8 \pm 1.1$ & 2 & $7.5 \pm 0.5$ \\
\hline 16 & 3 & $13.0 \pm 2.6$ & 3 & $8.7 \pm 1.3$ \\
\hline 17 & 4 & $4.8 \pm 0.5$ & 3 & $6.3 \pm 0.7$ \\
\hline 18 & 7 & $13.0 \pm 2.1$ & 3 & $6.7 \pm 1.8$ \\
\hline 19 & 10 & $9.2 \pm 1.6$ & 7 & $6.3 \pm 0.6$ \\
\hline 20 & 9 & $8.4 \pm 2.0$ & 7 & $9.0 \pm 2.3$ \\
\hline 21 & 2 & $16.5 \pm 4.5$ & 1 & 6.0 \\
\hline 22 & 6 & $10.0 \pm 2.2$ & 4 & $7.5 \pm 1.8$ \\
\hline 23 & 7 & $10.6 \pm 2.2$ & 1 & 8.0 \\
\hline 24 & 9 & $12.9 \pm 2.3$ & 6 & $7.7 \pm 0.9$ \\
\hline 25 & 2 & $13.5 \pm 5.5$ & 1 & 10.0 \\
\hline 26 & 13 & $10.5 \pm 1.6$ & 5 & $7.2 \pm 1.6$ \\
\hline 27 & 6 & $9.7 \pm 2.1$ & 5 & $7.2 \pm 0.8$ \\
\hline 28 & 4 & $14.8 \pm 5.1$ & 2 & $5.5 \pm 0.5$ \\
\hline 29 & 3 & $15.7 \pm 5.3$ & --- & --- \\
\hline 30 & --- & --- & --- & --- \\
\hline 31 & 1 & 19.0 & --- & --- \\
\hline
\end{tabular}

F0-related and temporal parameters were measured from groans of 20 different males while formant dispersion was measured from groans of 12 different males.

It was not always possible to measure the fundamental frequency and formants of the same groans for all males because of variation in the recording conditions. Sound frequencies degrade with distance according to the physical characteristics of the environment and lower frequencies are generally less susceptible to attenuation (McComb et al. 2003). In our study, recordings that were suitable for formant analysis were therefore more difficult to obtain than those on which F0-related parameters can be 
measured. In addition, the groaning activity (both in terms of number of vocal males and time spent vocalizing) changes during the rut (McElligott et al. 1999). As a result, sample sizes (number of groans and number of males) varied between analyses (Table 1). In total, we analysed recordings of 20 different males (six in 2002, one in 2003 and 13 in 2004). All six males in 2002 gained matings, the male from 2003 did not mate, and matings were not recorded in 2004 (Vannoni 2007). For the same males, we also calculated the groaning rate per min by dividing the number of groans of each recording sequence by the duration of the sequence. We collected our recordings using the all-occurrence sampling technique. This technique allows determination of a reliable estimate of the rate of occurrence and the temporal changes of a particular behaviour (e.g. vocalizing) in a population (Altmann 1974). Data for the F0-related and temporal parameters were available for 9-31 October (except on 30 October). Data for the formant frequencies were available for 9-28 October (except on 14 October). Data for groaning rate were available for 8-31 October.

Figure 2. Distribution of matings throughout the rut for 1992-1995 and 2002-2003. The four time periods (premating rut, early rut, middle rut and late rut) used for descriptive statistics are indicated. Recording of groans was carried out from 2002 to 2004; mating data were not available for 2004.

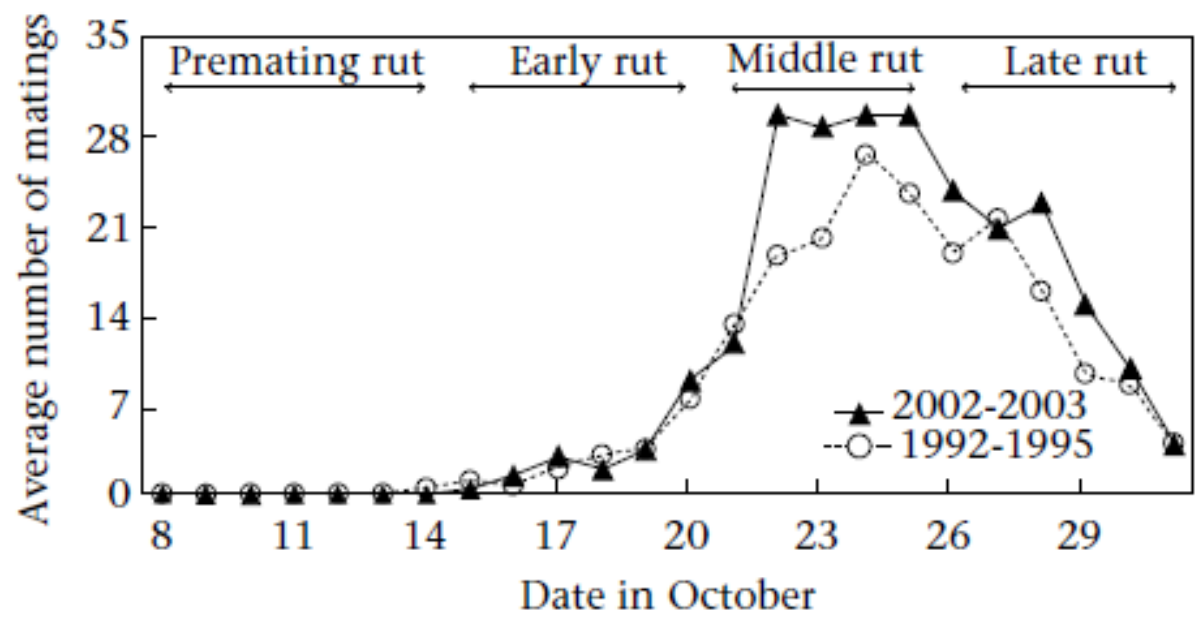

For descriptive purposes we calculated values of the acoustic parameters and of the groaning rate in time periods across the rut. We grouped the days of the rut into four time periods based on the distribution of the observed matings (and therefore the mating opportunities) during this time, which is very consistent across many years (unpublished data; Fig. 2; McElligott 1997; Vannoni 2007). Because the number of matings is not constant across the rut, the four time periods differ slightly in length. The first time period (premating rut, 7 days) includes those days during which matings do not usually occur or occur very rarely. During the second time period (early rut, 6 days), the number of matings increases but overall only a small proportion (15\% or less) of the total number of matings had usually occurred. The third time period (middle rut, 5 days) represents the peak of matings and the fourth time period (late rut, 6 days) includes the days from the peak to the end of the rut, during which the number of matings declines sharply.

Both F0 and formant frequencies are potentially involved in individual recognition in fallow deer (Vannoni \& McElligott 2007). We therefore measured the day-to-day changes in these parameters to estimate whether the information about individual identity may be reliably transmitted as the rut progressed. Dayto-day changes for the other parameters are reported for descriptive purposes. These changes were 
calculated by measuring the difference in the value of the acoustic parameter between 2 consecutive days. Then, we divided this number by the value of the first of the 2 days, and multiplied it by 100 .

\section{Statistical Analysis and Data}

We used a general linear mixed-effect model (GLMM) procedure fitted with residual maximum likelihood estimation (REML, Ime function; Venables \& Ripley 2002) to investigate the effect of day of the rut on the acoustic parameters of groans (F0-related and temporal parameters: 1107 groans; $55.3 \pm 4.7$ per individual, $N=20$; formant dispersion: 454 groans; $37.8 \pm 5.0$ per individual; $N=12$ ) and on the groaning rate (235 sequences; $11.7 \pm 1.2$ per individual; $N=20$ ). The acoustic parameters of each analysed groan as well as groaning rates were averaged within each male for each day of the rut. Individual identity nested within year of recording was fitted as a random term. In this way, we controlled for repeated measurements of the same individual during the rut and for pooling data from different years of recording. Based on the figures (see Results for examples) showing the relationships between the acoustic parameters and the days of the rut, we fitted as fixed effects either linear or curvilinear terms (quadratic and cubic). When more than one model was applied (e.g. F0-related parameters), and both were significant, the best model was assessed based on the Akaike information criterion (AIC; Burnham \& Anderson 2002; Vannoni \& McElligott 2008). Normal distributions of the data were determined by visually inspecting Q-Q plots and scatterplots of the residuals of the dependent variables. All tests were two tailed and factors were considered to have a statistically significant influence if $P<0.05$. All means are given with SEs.

Table 2. Descriptive statistics $(\bar{X} \pm S E)$ for the acoustic parameters of groans and groaning rate for each time period (premating rut, early rut, middle rut and late rut) of the rut (during October)

\begin{tabular}{|c|c|c|c|c|}
\hline Acoustic parameter & $\begin{array}{l}\text { Premating rut } \\
\text { (8-14 Oct) }\end{array}$ & $\begin{array}{l}\text { Early rut } \\
\text { (15-20 Oct) }\end{array}$ & $\begin{array}{l}\text { Middle rut } \\
\text { (21-25 Oct) }\end{array}$ & $\begin{array}{l}\text { Late rut } \\
\text { (26-31 Oct) }\end{array}$ \\
\hline \multicolumn{5}{|l|}{ Fo-related } \\
\hline $\mathrm{FO}_{\text {mean }}(\mathrm{Hz})$ & $28.1 \pm 0.9$ & $27.0 \pm 0.4$ & $25.7 \pm 0.5$ & $27.5 \pm 0.5$ \\
\hline $\mathrm{FO}_{\min }(\mathrm{Hz})$ & $22.5 \pm 0.5$ & $21.2 \pm 0.1$ & $21.3 \pm 0.4$ & $22.4 \pm 0.3$ \\
\hline $\mathrm{FO}_{\max }(\mathrm{Hz})$ & $34.3 \pm 1.3$ & $33.3 \pm 1.0$ & $31.1 \pm 0.8$ & $33.5 \pm 0.9$ \\
\hline Jitter (Hz) & $13.5 \pm 0.9$ & $13.2 \pm 0.9$ & $12.7 \pm 0.3$ & $14.1 \pm 0.9$ \\
\hline \multicolumn{5}{|l|}{ Temporal } \\
\hline Pulses & $10.2 \pm 0.3$ & $9.9 \pm 0.1$ & $8.9 \pm 0.2$ & $8.9 \pm 0.4$ \\
\hline Duration (ms) & $351.2 \pm 6.2$ & $353.9 \pm 7.7$ & $330.7 \pm 10.4$ & $307.0 \pm 11.1$ \\
\hline \multicolumn{5}{|l|}{ Formant-related } \\
\hline $\mathrm{F} 1_{\min }(\mathrm{Hz})$ & $195.3 \pm 3.6$ & $207.4 \pm 3.9$ & $204.6 \pm 4.8$ & $185.9 \pm 6.0$ \\
\hline $\mathrm{F} 2 \min (\mathrm{Hz})$ & $413.5 \pm 1.2$ & $414.3 \pm 5.3$ & $402.2 \pm 3.0$ & $407.3 \pm 3.9$ \\
\hline $\mathrm{F} 3_{\min }(\mathrm{Hz})$ & $553.9 \pm 9.2$ & $568.3 \pm 9.6$ & $576.5 \pm 10.6$ & $565.7 \pm 13.5$ \\
\hline $\mathrm{F} 4_{\min }(\mathrm{Hz})$ & $1060.8 \pm 6.5$ & $1058.1 \pm 3.7$ & $1032.8 \pm 6.7$ & $1076.4 \pm 1.6$ \\
\hline $\mathrm{F} 5_{\min }(\mathrm{Hz})$ & $1258.3 \pm 4.8$ & $1271.5 \pm 8.0$ & $1252.6 \pm 8.4$ & $1283.4 \pm 6.8$ \\
\hline $\mathrm{F} 6_{\min }(\mathrm{Hz})$ & $1814.0 \pm 12.2$ & $1787.2 \pm 4.1$ & $1748.0 \pm 16.5$ & $1803.2 \pm 8.8$ \\
\hline$D f_{\min }(\mathrm{Hz})$ & $300.1 \pm 1.4$ & $299.3 \pm 1.3$ & $293.9 \pm 2.1$ & $301.8 \pm 1.4$ \\
\hline Groaning rate (groans $/ \mathrm{min}$ ) & $23.9 \pm 3.1$ & $32.8 \pm 2.0$ & $44.7 \pm 1.1$ & $32.5 \pm 2.6$ \\
\hline
\end{tabular}


Table 3. Average day-to-day changes \pm SE in the acoustic parameters of groans

\begin{tabular}{|c|c|c|c|}
\hline Acoustic parameter & Day-to-day change (\%) & Range & $N$ \\
\hline \multicolumn{4}{|l|}{ F0-related } \\
\hline $\mathrm{FO}_{\text {mean }}(\mathrm{Hz})$ & $4.5 \pm 0.5$ & $0.1-8.4$ & 21 \\
\hline $\mathrm{FO}_{\min }(\mathrm{Hz})$ & $2.8 \pm 0.4$ & $0.3-7.7$ & 21 \\
\hline $\mathrm{FO}_{\max }(\mathrm{Hz})$ & $6.6 \pm 0.9$ & $0.9-13.7$ & 21 \\
\hline Jitter $(\mathrm{Hz})$ & $15.9 \pm 2.6$ & 1.1-36.7 & 21 \\
\hline \multicolumn{4}{|l|}{ Temporal } \\
\hline Pulses & $6.9 \pm 1.3$ & $0.1-20.1$ & 21 \\
\hline Duration (ms) & $7.2 \pm 1.0$ & $0.1-20.8$ & 21 \\
\hline \multicolumn{4}{|l|}{ Formant-related } \\
\hline $\mathrm{F} 1_{\min }(\mathrm{Hz})$ & $7.3 \pm 1.1$ & $1.9-19.2$ & 19 \\
\hline $\mathrm{F} 2_{\min }(\mathrm{Hz})$ & $2.0 \pm 0.4$ & $0.2-7.1$ & 19 \\
\hline $\mathrm{F} 3_{\min }(\mathrm{Hz})$ & $5.1 \pm 0.8$ & $0.5-12.0$ & 19 \\
\hline $\mathrm{F} 4_{\text {min }}(\mathrm{Hz})$ & $1.7 \pm 0.3$ & $0.0-4.7$ & 19 \\
\hline $\mathrm{F} 5_{\min }(\mathrm{Hz})$ & $1.2 \pm 0.3$ & $0.0-4.5$ & 19 \\
\hline $\mathrm{F} 6_{\min }(\mathrm{Hz})$ & $1.5 \pm 0.3$ & $0.3-4.3$ & 19 \\
\hline$D f_{\min }(\mathrm{Hz})$ & $1.2 \pm 0.2$ & $0.3-3.0$ & 19 \\
\hline
\end{tabular}

$N$ refers to the number of intervals (each interval being the difference between two consecutive measurements of the parameter) considered.

Table 4. General linear mixed-effect models to investigate the effect of day of the rut on the acoustic parameters of groans and groaning rate

\begin{tabular}{|c|c|c|c|c|c|c|c|}
\hline \multirow[t]{2}{*}{ Parameters } & \multirow[t]{2}{*}{$d f$} & \multicolumn{2}{|c|}{ Day of rut } & \multicolumn{2}{|c|}{ Day of rut ${ }^{2}$} & \multicolumn{2}{|c|}{ Day of rut ${ }^{3}$} \\
\hline & & $F$ & $P$ & $F$ & $P$ & $F$ & $P$ \\
\hline \multicolumn{8}{|l|}{ F0-related } \\
\hline $\mathrm{FO}_{\text {mean }}(\mathrm{Hz})$ & 84 & --- & --- & 0.17 & 0.68 & 0.51 & 0.47 \\
\hline $\mathrm{FO}_{\min }(\mathrm{Hz})$ & 84 & --- & --- & 11.17 & 0.001 & 13.34 & $<0.001$ \\
\hline $\mathrm{FO}_{\max }(\mathrm{Hz})$ & 84 & --- & --- & 0.17 & 0.68 & 0.04 & 0.84 \\
\hline Jitter (Hz) & 84 & --- & --- & 0.02 & 0.89 & 0.05 & 0.82 \\
\hline \multicolumn{8}{|l|}{ Temporal } \\
\hline Pulses & 84 & 24.40 & $<0.001$ & --- & --- & --- & --- \\
\hline Duration (ms) & 84 & 25.26 & $<0.001$ & --- & --- & --- & --- \\
\hline \multicolumn{8}{|l|}{ Formant-related } \\
\hline $\mathrm{Df}_{\min }(\mathrm{Hz})$ & 49 & --- & --- & 0.28 & 0.60 & --- & --- \\
\hline Rate (groans/min) & 111 & --- & --- & 31.24 & $<0.001$ & --- & --- \\
\hline
\end{tabular}

Linear (Day of rut), quadratic (Day of rut ${ }^{2}$ ) and cubic terms (Day of rut ${ }^{3}$ ) were fitted as fixed effects. 


\section{RESULTS}

\section{Acoustic Parameters of Groans}

Descriptive statistics of the acoustic parameters over the four time periods of the rut used in our analyses are given in Table 2. The average day-to-day changes are also given (Table 3). Daily changes in F0related and temporal parameters were generally higher than those for formant-related parameters (Table $3)$.

$\mathrm{FO}_{\min }$ varied significantly over the course of the rut (Table 4). In the regression models, both the quadratic and the cubic terms were significant for $\mathrm{FO}_{\min }$. However, the quadratic relationship ( $\mathrm{AIC}=388.06$ ) showed an AIC value of 5 units $(\triangle A I C)$ lower than the cubic one $(A I C=393.12)$, and therefore this was the model best supported by the data. $\mathrm{FO}_{\min }$ was higher at the beginning and end of the rut than during the middle (Fig. 3a). The directions of changes of $\mathrm{FO}_{\text {mean }}, \mathrm{FO}_{\max }$ and Jitter during the rut were similar to that of $\mathrm{FO}_{\min }$, but they were not significant (Table 4). Pulses and duration showed a significant linear decrease as the rut progressed (Table 4, Fig. 3c, d). The minimum formant dispersion did not change significantly (Table 4).

\section{Groaning Rate}

Groaning rate was calculated for $5.54 \pm 0.55$ (range 1-12) different males for each day of the rut. We used $1.75 \pm 0.12$ (range 1-8) recording sequences (sequence length: $0.78 \pm 0.38 \mathrm{~min}$ ) for each male on every single day. Descriptive statistics of the groaning rates during the four time periods of the rut are given in Table 2. The average day-to-day variation was $21.5 \pm 4.1 \%(N=24$; range $0.5-71.3 \%)$. Groaning rate varied significantly over the course of the rut (Table 4 ), increasing towards the peak of the rut and then decreasing until the end (Fig. 4).

\section{DISCUSSION}

We investigated individual changes in the acoustic structure and call rate of fallow buck groans, as the rut progressed. We found that the acoustic structure and the groaning rate changed. The minimum fundamental frequency (FOmin) was lowest during the middle of the rut (when matings were most common) and highest at the beginning and at the end, whereas the temporal parameters (number of pulses and duration of the groans) decreased linearly towards the end of the rut. By contrast, the minimum formant dispersion $\left(\mathrm{Df}_{\mathrm{min}}\right)$ showed minor changes and therefore remained relatively stable during the rut. Groaning rate rapidly increased from the beginning to the peak and then decreased over the last days of the rut. Previous research has shown that formant-related acoustic parameters of sexually selected calls are individually distinctive and related to the body size of the caller (Fischer et al. 2002, 2004; Reby \& McComb 2003; Sanvito et al. 2007; Vannoni \& McElligott 2007, 2008). Because body size is generally fixed among adult individuals, at least part of the acoustic structure of these calls should be rather stable over time. Our results confirm this hypothesis but at the same time show that formantindependent acoustic characteristics and the calling rates can change over a short period of a few weeks. This probably results from variation in traits related to the current condition of the caller, as well as changes in the availability of mating opportunities and the intensity of male-male competition.

Fallow buck groans are individually distinctive with $\mathrm{FO}_{\text {min }}$ and the minimum frequency of the higher formants $\left(F 4_{\min }-F 6_{\min }\right.$ ) contributing most to the interindividual variation (Vannoni \& McElligott 2007). In this earlier study, we only included groans recorded prior to 19 October (see Fig. 2) to minimize the possible effects of male condition loss. The alteration of acoustic signals that contain individual signature 
information represents a potential obstacle for individual recognition of vocalizations. In humans, voice individuality is retained over a wide pitch range, especially towards the low-frequency region (Kuwabara \& Takagi 1991). By contrast, the perception of voice individuality is significantly affected by changes in formant frequencies and is seriously compromised by a formant shift of approximately $5 \%$ of the original formants (Kuwabara \& Takagi 1991). Based on this knowledge, our results suggest that the degree of variation shown by $\mathrm{FO}_{\min }$ and $\mathrm{F} 4_{\min }-\mathrm{F} 6_{\min }$ during the rut should ensure the individually distinctive characteristics of fallow buck groans. Furthermore, a study of individual variation in red deer, Cervus elaphus, mating calls using advanced statistical methods showed that filter-related features enabled individual recognition in the absence of FO characteristics (Reby et al. 2006). Playback experiments are necessary to test recognition by other individuals, when call structure varies.

Figure 3. (a), $\mathrm{FO}_{\min }$ (b), $\mathrm{FO}_{\text {mean }}$ (c) number of pulses and (d) duration of the groan over the course of the rut. The mean of each of these related acoustic parameters among the males was calculated. The error bars show SEMs. Data on the F0-related and temporal parameters were available for 9-31 October (except October 30).
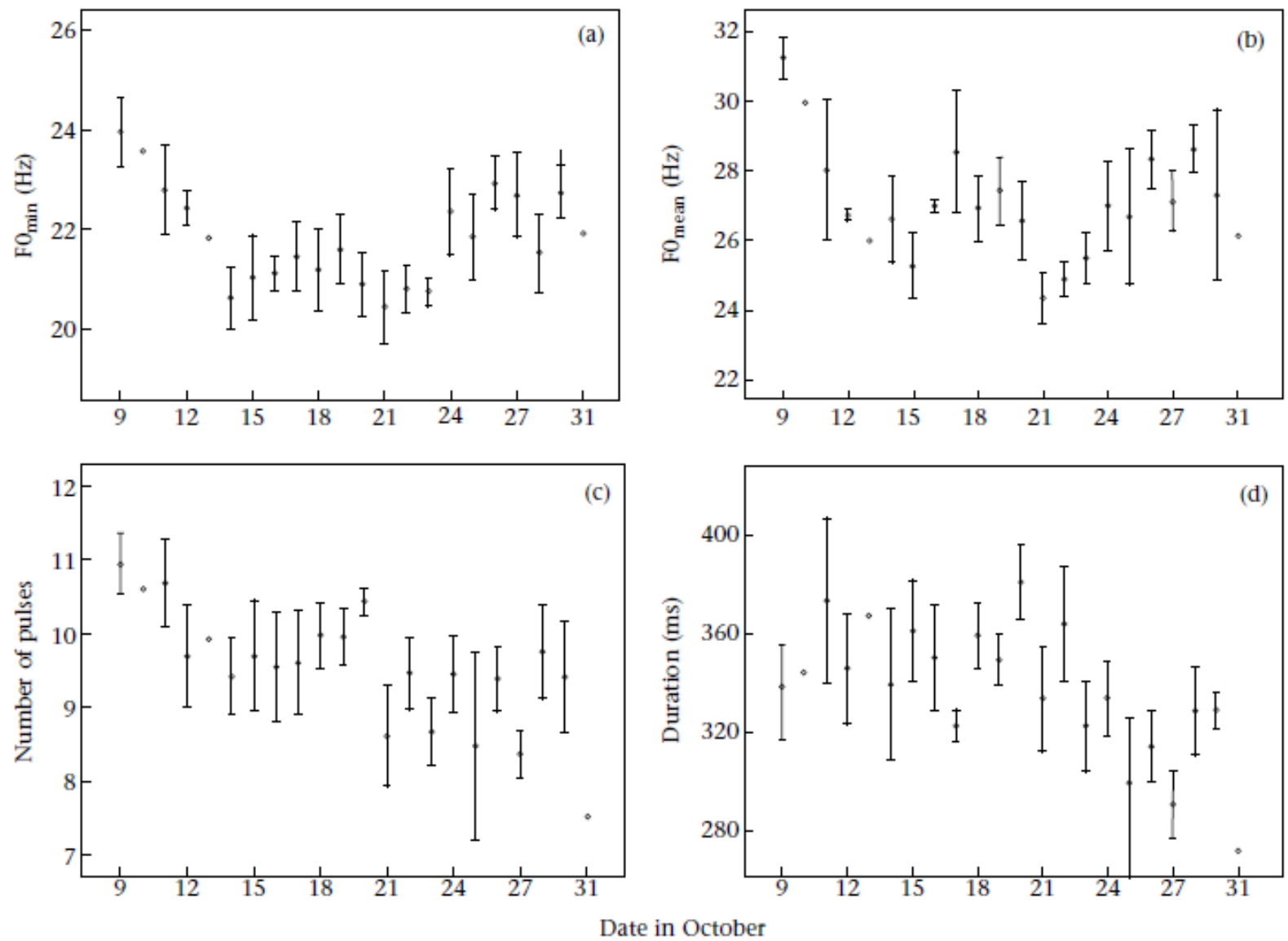

We found that $\mathrm{FO}_{\min }$ changes followed a curvilinear trend over the course of the rut. FOmin showed a decline during the first few days of the rut and then remained relatively stable until the peak. The initial decline of $\mathrm{FO}_{\min }$ may be caused by a vocal 'warm-up' effect in the muscles used when calling, which reduces their viscosity (Safran et al. 1989). A decrease in viscosity in laryngeal musculature induces a decrease in phonation threshold pressure (Titze 1988) and therefore in F0. Fallow bucks are silent for most of the year and may therefore experience a vocal warm-up phase at the beginning of the rut. After this phase, the increase in both physical and vocal activity may force males to vocalize at the upper limits 
of stable vocal fold vibration, therefore leading to an increase in FO as a result of vocal fatigue (Laukkanen \& Kankare 2006).

Figure 4. Groaning rates (groans/min) during the course of the rut. The mean of the groaning rate among the males was calculated. The error bars show SEMs. Data on groaning rates were available for 8-31 October.

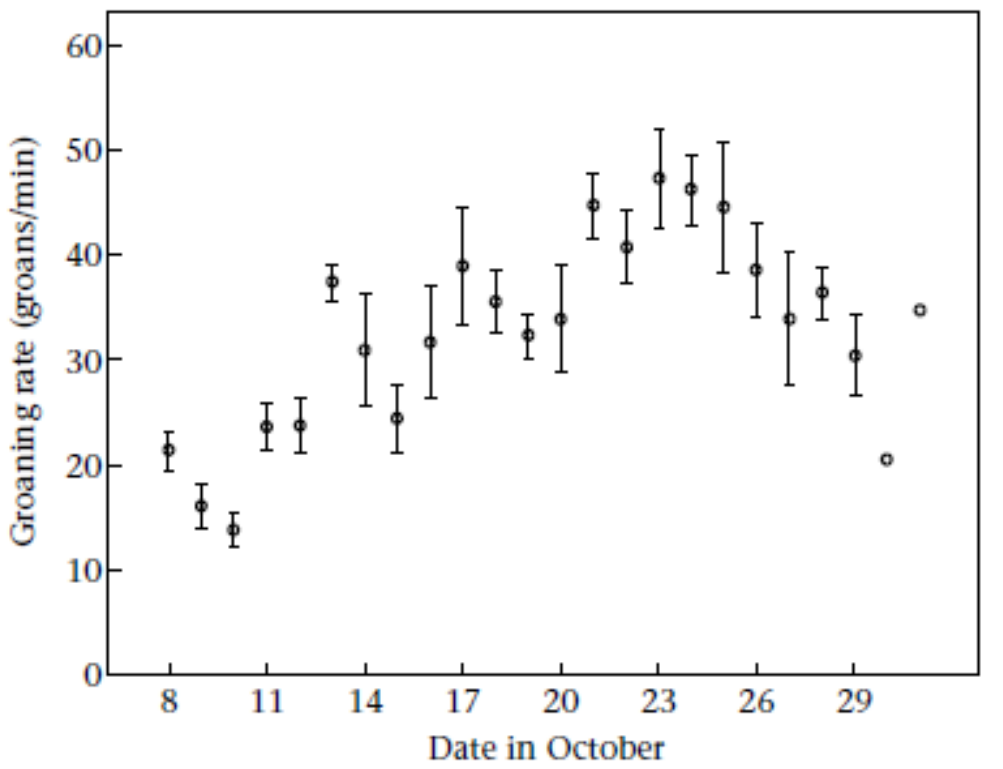

Higher-ranked fallow bucks produce groans with lower $\mathrm{FO}_{\min }$ (Vannoni \& McElligott 2008), suggesting that this parameter can signal male quality (Apicella et al. 2007). The production of low-pitched calls at a high vocalization rate may in turn significantly increase the effort and control required to maintain the performance of the vocal production. Calls indicating a stable and regular vibration of the vocal folds could therefore signal better physical condition of the caller (Riede et al. 2007). This would be particularly important during the days that precede the peak of the rut when most of the females approach oestrus and are therefore likely to choose among prospective males (Komers et al. 1999; Farrell 2001). At the peak of the rut, $\mathrm{FO}_{\min }$ increased and stayed at a high level until the end of the rut. The degree of energetic expenditure resulting from conspicuous displays occurring at this time is very high, especially if the loss in weight that males undergo during the rut is considered (McElligott et al. 2003). If the production of groans with low $\mathrm{FO}_{\min }$ communicates better physical condition, then it would always be advantageous for males to produce these groans. Affording such costs might not be possible from the peak of the rut onwards because of physical exhaustion. This, together with the physiological and biomechanical mechanisms at the basis of acoustic alterations caused by prolonged vocal effort, may lead to pitch perturbations and a consequent increase in F0 (Welham \& Maclagan 2003; Laukkanen \& Kankare 2006).

Changes occurring in $\mathrm{FO}_{\text {mean }}$ and $\mathrm{FO}_{\text {max }}$ followed the same direction as those of $\mathrm{FO}_{\text {min }}$, with values decreasing from the beginning to the peak of the rut and increasing during the late rut. However, these changes were not significant. In general, the profiles followed by $\mathrm{FO}_{\text {mean }}$ and $\mathrm{FO}_{\text {max }}$ changes are less clear because of a higher interindividual variation. This is also probably the reason why the relatively larger frequency changes in Jitter do not follow a specific distribution during the rut. Within-individual variation in $\mathrm{FO}_{\text {mean }}, \mathrm{FO}_{\max }$ and Jitter may have the potential to reveal the effects of momentary emotional states as they occur (Soltis et al. 2005; Theis et al. 2007). The analysis of groans recorded immediately before, during and after fighting, for example, could be used to test this hypothesis. 
The number of pulses and the duration of the groans gradually decreased as the rut progressed. These variables are closely related to F0, but it is possible that any or all of these variables have biological relevance, and may be used for information gathering by conspecifics. Longer calls are usually produced at slower rates, thereby keeping aerobic metabolic costs relatively constant (Wells \& Taigen 1986; Kajikawa \& Hasegawa 2000). However, as changes in groaning rate and temporal parameters followed a different distribution (curvilinear and linear, respectively) over time, this seems not to be the case in our study. Fallow bucks lose an average of $26 \%$ of their body mass during the rut (McElligott et al. 2003). This decline in body condition, caused by a dramatic reduction in forage intake and increased energy expenditure, is likely to occur gradually and this is reflected in the linear reduction in the number of pulses, and consequently in the duration of the groans. If conspecifics can detect changes in temporal features of groans, such as the number of pulses, this could be the key variable used by them when assessing current male condition.

We found that the minimum formant dispersion $\left(\mathrm{Df}_{\mathrm{min}}\right)$ did not change significantly during the rut. Single formants (especially the lower ones) may vary because the articulatory movements and therefore the vocal tract shape change with different vocalizations (Rendall et al. 1998). However, this does not affect the overall formant dispersion. Fallow bucks are therefore always able to pull down the larynx to the same level despite changes in motivation, physical activity and groaning rate (McElligott et al. 2006; Vannoni \& McElligott 2007). Formant frequencies have been shown to be less sensitive to vocal effort than fundamental frequency (Liénard \& Di Benedetto 1999). Moreover, acoustic alteration caused by changes in motivation mainly affects the activity of the larynx and not that of the vocal tract. A stable $\mathrm{Df}_{\text {min }}$ through the rut allows the information about body size of the males to be always reliably conveyed.

Groaning rates changed dramatically over the course of the rut. Previous research has shown that they vary according to different social contexts and suggests that short-term changes in groaning rates mainly represent a threat signal directed to other males (McElligott \& Hayden 1999, 2001). In our study, we did not take into consideration the specific social context of groan production. Nevertheless, groaning rates followed a clear curvilinear trend, reaching their highest levels at the peak of the rut when most matings occurred, and were lower during the early and late rut. This suggests that groaning rates might change according to changes in motivation caused by variation in the number of females available for mating. The presence of more females in oestrus, and more rivals attempting to gain access to them, could result in a higher level of arousal in the caller, resulting in changes to breathing rates and groaning rates (Scherer 2003). The rapid decrease in groaning rate at the end of the rut may also be partly explained by the decline in male body condition (see also Clutton-Brock \& Albon 1979).

The males included in this study are among those that vocalized through most of the rut and they are also generally the successful males (high dominance rank and mating success). These males start vocalizing early in October (or indeed late September), lose a great deal of body condition, and start producing hoarse groans late in the rut when they also get challenged by formerly subordinate males (McElligott et al. 1998, 1999; E. Vannoni \& A.G. McElligott, personal observation). Some prime-aged males (5-8 years old, McElligott et al. 2002) stop vocalizing and trying to gain matings before the end of the rut, and leave traditional rutting areas (E. Vannoni \& A.G. McElligott, personal observation). Therefore these males could not be included in our study, although they also probably experience some or all of the changes in vocalizations documented here.

There are many examples of sexually selected traits functioning both intrasexually as a threat signal and intersexually as an advertisement (Berglund et al. 1996; Bernal et al. 2009). The vocal behaviour of fallow bucks represents a unimodal multicomponent signal that potentially provides very reliable honest information about different aspects of males (Johnstone 1996; Candolin 2003; Vannoni \& McElligott 2008). Acoustic components that are stable throughout the rut are likely to be of greater interest to 
females in terms of mate choice (Komers et al. 1999; Farrell 2001), because they would allow females to identify high-quality males even when they have lost a great deal of body condition. By contrast, dynamic acoustic features that decline during the latter part of the rut and potentially signal fatigue and loss of body condition are likely to be more useful for males when assessing competitors and deciding whether to challenge and fight (McElligott et al. 1998; Briffa \& Sneddon 2007). While Dale et al. (2001) suggested that characters selected to signal individual identity have properties differing from those expected for indicator signals of quality, we found stable and changing features in the same acoustic parameters of groans that code for both identity and quality, as the rut progressed (Vannoni \& McElligott 2007, 2008).

Finally, we suggest that the audible breakdown in call structure late in the breeding season might be a widespread communication phenomenon among species in which males are highly vocal and active during the breeding season, leading to reduced food consumption and consequent fatigue (Clutton-Brock \& Albon 1979; Bevier 1997; Frey et al. 2007a, b; Sanvito et al. 2007; Kunc \& Wolf 2008; Mitchell et al. 2008; Wyman et al. 2008; Brumm et al. 2009). We believe that the importance of this change, in signalling current body condition to conspecifics, has generally not been considered and therefore requires further investigation.

\section{Acknowledgments}

We are grateful to Maurus Birrer and Marco Torriani for field assistance, Hansjörg Kunc and Kamran Safi for statistical help, and Elodie Briefer, Olivia Curno, David Reby and an anonymous referee for comments on the manuscript. We acknowledge the financial support of the Forschungskommission der Universität Zürich to A. G. McElligott, and the Swiss Academy of Sciences to E. Vannoni. We thank staff of Phoenix Park and University College Dublin for their assistance.

\section{References}

Altmann, J. 1974. Observational study of behavior-sampling methods. Behaviour, 49, 227-267.

Apicella, C. L., Feinberg, D. R. \& Marlowe, F. W. 2007. Voice pitch predicts reproductive success in male hunter-gatherers. Biology Letters, 3, 682-684.

Bachorowski, J. \& Owren, M. J. 2003. Sounds of emotion: production and perception of affected-related vocal acoustics. Annals of the New York Academy of Sciences, 1000, 244-265.

Berglund, A., Bisazza, A. \& Pilastro, A. 1996. Armaments and ornaments: an evolutionary explanation of traits of dual utility. Biological Journal of the Linnean Society, 58, 385-399.

Bernal, X. E., Rand, A. S. \& Ryan, M. J. 2009. Task differences confound sex differences in receiver permissiveness in túngara frogs. Proceedings of the Royal Society B, 276, 1323-1329.

Bevier, C. R. 1997. Utilization of energy substrates during calling activity in tropical frogs. Behavioral Ecology and Sociobiology, 41, 343-352.

Briffa, M. \& Sneddon, L. U. 2007. Physiological constraints on contest behaviour. Functional Ecology, 21, 627-637.

Brumm, H., Lachlan, R. F., Riebel, K. \& Slater, P. J. B. 2009. On the function of song type repertoires: testing the 'antiexhaustion hypothesis' in chaffinches. Animal Behaviour, 77, 37-42.

Burnham, K. P. \& Anderson, D. R. 2002. Model Selection and Multimodel Inference: a Practical Information-Theoretic Approach, 2nd edn. New York: Springer.

Candolin, U. 2003. The use of multiple cues in mate choice. Biological Reviews, 78, 575-595.

Charlton, B., Reby, D. \& McComb, K. 2007a. Female perception of size-related formant shifts in red deer, Cervus elaphus. Animal Behaviour, 74, 707-714.

Charlton, B., Reby, D. \& McComb, K. 2007b. Female red deer prefer the roars of larger males. Biology Letters, 3, 383-385. 
Clutton-Brock, T. H. \& Albon, S. D. 1979. The roaring of red deer and the evolution of honest advertisement. Behaviour, 69, 145-170.

Dabbs, J. M. \& Mallinger, A. 1999. High testosterone levels predict low voice pitch among men. Personality and Individual Differences, 27, 801-804.

Dale, J., Lank, D. B. \& Reeve, H. K. 2001. Signaling individual identity versus quality: a model and case studies with ruffs, queleas, and house finches. American Naturalist, 158, 75-86.

Elowson, A. M. \& Snowdon, C. T. 1994. Pygmy marmosets, Cebuella pygmaea, modify vocal structure in response to changed social environment. Animal Behaviour, 47, 1267-1277.

Farrell, M. E. 2001. Courtship, multiple mating and reproductive synchrony in female fallow deer (Dama dama). Ph.D. thesis, University College Dublin.

Fichtel, C. \& Hammerschmidt, K. 2002. Responses of red-fronted lemurs to experimentally modified alarm calls: evidence for urgency-based changes in call structure. Ethology, 108, 763-777.

Fischer, J., Hammerschmidt, K., Cheney, D. L. \& Seyfarth, R. M. 2002. Acoustic features of male baboon loud calls: influences of context, age, and individuality. Journal of the Acoustical Society of America, 111, 1465-1474.

Fischer, J., Kitchen, D. M., Seyfarth, R. M. \& Cheney, D. L. 2004. Baboon loud calls advertise male quality: acoustic features and their relation to rank, age, and exhaustion. Behavioral Ecology and Sociobiology, 56, 140-148.

Frey, R., Volodin, I. \& Volodina, E. 2007a. A nose that roars: anatomical specializations and behavioural features of rutting male saiga. Journal of Anatomy, 211, 717-736.

Frey, R., Gebler, A., Fritsch, G., Nygre'n, K. \& Weissengruber, G. E. 2007b. Nordic rattle: the hoarse vocalization and the inflatable laryngeal air sac of reindeer (Rangifer tarandus). Journal of Anatomy, 210, 131-159.

Horii, Y. 1979. Fundamental frequency perturbation observed in sustained phonation. Journal of Speech and Hearing Research, 22, 5-19.

Johnstone, R. A. 1996. Multiple displays in animal communication: 'backup signals' and 'multiple messages'. Philosophical Transactions of the Royal Society, of London, Series B, 351, 329-338.

Jorgensen, D. D. \& French, J. A. 1998. Individuality but not stability in marmoset long calls. Ethology, 104, 729-742.

Kajikawa, S. \& Hasegawa, T. 2000. Acoustic variation of pant hoot calls by male chimpanzees: a playback experiment. Journal of Ethology, 18, 133-139.

Komers, P. E., Birgersson, B. \& Ekvall, K. 1999. Timing of estrus in fallow deer is adjusted to the age of available mates. American Naturalist, 153, 431-436.

Koren, L. \& Geffen, E. 2009. Complex call in male rock hyrax (Procavia capensis): a multi-information distributing channel. Behavioral Ecology and Sociobiology, 63, 581-590.

Kunc, H. P. \& Wolf, J. B. W. 2008. Seasonal changes in vocal rates and their relation to territorial status in male Galapagos sea lions (Zalophus wollebaeki). Ethology, 114, 381-388.

Kuwabara, H. \& Takagi, T. 1991. Acoustic parameters of voice individuality and voice-quality control by analysis-synthesis method. Speech Communication, 10, 491-495.

Laukkanen, A. M. \& Kankare, E. 2006. Vocal loading-related changes in male teachers' voices investigated before and after a working day. Folia Phoniatrica et Logopaedica, 58, 229-239.

Lie'nard, J.-S. \& Di Benedetto, M.-G. 1999. Effect of vocal effort on spectral properties of vowels. Journal of the Acoustical Society of America, 106, 411-422.

McComb, K. E. 1991. Female choice for high roaring rate in red deer, Cervus elaphus. Animal Behaviour, 41, 79-88.

McComb, K., Reby, D., Baker, L., Moss, C. \& Sayialel, S. 2003. Long-distance communication of acoustic cues to social identity in African elephants. Animal Behaviour, 65, 317-329. 
McElligott, A. G. 1997. Fighting, vocal activity, annual mating success and lifetime mating success of fallow bucks (Dama dama L.): short-term investment and long-term cost. Ph.D. thesis, University College Dublin.

McElligott, A. G. \& Hayden, T. J. 1999. Context-related vocalization rates of fallow bucks, Dama dama. Animal Behaviour, 58, 1095-1104.

McElligott, A. G. \& Hayden, T. J. 2001. Postcopulatory vocalizations of fallow bucks: who is listening? Behavioral Ecology, 12, 41-46.

McElligott, A. G., Mattiangeli, V., Mattiello, S., Verga, M., Reynolds, C. A. \& Hayden, T. J. 1998. Fighting tactics of fallow bucks (Dama dama, Cervidae): reducing the risks of serious conflict. Ethology, 104, 789-803.

McElligott, A. G., O'Neill, K. P. \& Hayden, T. J. 1999. Cumulative long-term investment in vocalization and mating success of fallow bucks, Dama dama. Animal Behaviour, 57, 1159-1167.

McElligott, A. G., Altwegg, R. \& Hayden, T. J. 2002. Age-specific survival and reproductive probabilities: evidence for senescence in male fallow deer (Dama dama. Proceedings of the Royal Society B, 269, 1129-1137.

McElligott, A. G., Naulty, F., Clarke, W. \& Hayden, T. J. 2003. The somatic cost of reproduction: what determines reproductive effort in prime-aged fallow bucks? Evolutionary Ecology Research, 5, 1239-1250.

McElligott, A. G., Birrer, M. \& Vannoni, E. 2006. Retraction of the mobile descended larynx during groaning enables fallow bucks (Dama dama) to lower their formant frequencies. Journal of Zoology, 270, 340-345.

Manteuffel, M., Puppe, B. \& Schön, P. C. 2004. Vocalization of farm animals as a measure of welfare. Applied Animal Behaviour Science, 88, 163-182.

Mitani, J. C. \& Brandt, K. L. 1994. Social factors influence the acoustic variability in the long-distance calls of male chimpanzees. Ethology, 96, 233-252.

Mitchell, S., Poland, J. \& Fine, M. L. 2008. Does muscle fatigue limit advertisement calling in the oyster toadfish Opsanus tau? Animal Behaviour, 76, 1011-1016. Morton, E. S. 1977. On the occurrence and significance of motivation-structural rules in some birds and mammal sounds. American Naturalist, 111, 855-869.

Morton, E. S. 1982. Grading, discreteness, redundancy, and motivational-structural rules. In: Acoustic Communication in Birds, Vol. 1 (Ed. by D. E. Kroodsma \& E. H. Miller), pp. 183-212. New York: Academic Press.

Pfefferle, D., West, P. M., Grinnell, J., Packer, C. \& Fischer, J. 2007. Do acoustic features of lion, Panthera leo, roars reflect sex and male condition? Journal of the Acoustical Society of America, 121, 3947-3953.

Rantala, L., Maatta, T. \& Vilkman, E. 1997. Measuring voice under teachers' working circumstances: F-0 and perturbation features in maximally sustained phonation. Folia Phoniatrica et Logopaedica, 49, 281-291.

Reby, D. \& McComb, K. E. 2003. Anatomical constraints generate honesty: acoustic cues to age and weight in the roars of red deer stags. Animal Behaviour, 65, 519-530.

Reby, D., Joachim, J., Lauga, J., Lek, S. \& Aulagnier, S. 1998. Individuality in the groans of fallow deer (Dama dama) bucks. Journal of Zoology, 245, 79-84.

Reby, D., McComb, K. E., Cargnelutti, B., Darwin, C., Fitch, W. T. \& Clutton-Brock, T. H. 2005. Red deer stags use formants as assessment cues during intrasexual agonistic interactions. Proceedings of the Royal Society of London, Series B, 272, 941-947.

Reby, D., Andre-Obrecht, R., Galinier, A., Farinas, J. \& Cargnelutti, B. 2006. Cepstral coefficients and hidden Markov models reveal idiosyncratic voice characteristics in red deer (Cervus elaphus) stags. Journal of the Acoustical Society of America, 120, 4080-4089. 
Rendall, D. 2003. Acoustic correlates of caller identity and affect intensity in the vowel-like grunt vocalizations of baboons. Journal of the Acoustical Society of America, 113, 3390-3402.

Rendall, D., Owren, M. J. \& Rodman, P. S. 1998. The role of vocal tract filtering in identity cueing in rhesus monkey (Macaca mulatta) vocalizations. Journal of the Acoustical Society of America, 103, 602-614.

Riede, T., Arcadi, A. C. \& Owren, M. J. 2007. Nonlinear acoustics in the pant hoots of common chimpanzees (Pan troglodytes): vocalizing at the edge. Journal of the Acoustical Society of America, 121, 1758-1767.

Rolf, H. J. \& Fischer, K. 1990. Serum testosterone (T) and 5-alpha-dihydrotestosterone (DHT) in male fallow deer (Dama dama L.): seasonality and age dependence. Comparative Biochemistry and Physiology A, Physiology, 95, 445-452.

Rukstalis, M., Fite, J. \& French, J. A. 2003. Social changes affect vocal structure in a callitrichid primate (Callithrix kuhlii). Ethology, 109, 327-340.

Safran, M., Seaber, A. \& Garrett, W. 1989. Warm-up and muscular injury prevention: an update. Sports Medicine, 8, 239-249.

Sanvito, S., Galimberti, F. \& Miller, E. H. 2007. Vocal signalling of male southern elephant seals is honest but imprecise. Animal Behaviour, 73, 287-299.

Scherer, K. R. 2003. Vocal communication of emotion: a review of research paradigms. Speech Communication, 40, 227-256.

Semple, S. \& McComb, K. 2000. Perception of female reproductive state from vocal cues in a mammal species. Proceedings of the Royal Society B, 267, 707-712.

Soltis, J., Leong, K. \& Savage, A. 2005. African elephant vocal communication II: rumble variation reflects the individual identity and emotional state of the callers. Animal Behaviour, 70, 589-599.

Theis, K. R., Greene, K. M., Benson-Amram, S. R. \& Holekamp, K. E. 2007. Sources of variation in the long-distance vocalizations of spotted hyenas. Behaviour, 144, 557-584.

Titze, I. R. 1988. The physics of small-amplitude oscillation of the vocal folds. Journal of the Acoustical Society of America, 83, 1536-1552.

Titze, I. R. 1994. Principles of Voice Production. Upper Saddle River, New Jersey: Prentice Hall.

Titze, I. R., Horii, Y. \& Scherer, R. C. 1987. Some technical consideration in voice perturbation measurements. Journal of Speech and Hearing Research, 30, 252-260.

Torriani, M. V. G., Vannoni, E. \& McElligott, A. G. 2006. Mother-young recognition in an ungulate hider species: a unidirectional process. American Naturalist, 168, 412-420.

Vannoni, E. 2007. Natural and sexual selection at work: the structure and function of fallow deer (Dama dama) vocalizations. Ph.D. thesis, University of Zurich.

Vannoni, E. \& McElligott, A. G. 2007. Individual acoustic variation in fallow deer (Dama dama) common and harsh groans: a source-filter theory perspective. Ethology, 113, 223-234.

Vannoni, E. \& McElligott, A. G. 2008. Fundamental frequency and formant frequencies of groans encode information about male quality in fallow deer (Dama dama). PloS One, 3, e3113.

Vannoni, E., Torriani, M. V. G. \& McElligott, A. G. 2005. Acoustic signalling in cervids: a methodological approach for measuring vocal communication in fallow deer. Cognition, Brain, Behaviour, 9, 551566.

Venables, W. N. \& Ripley, B. D. 2002. Modern Applied Statistics with S, 4th edn. New York: Springer.

Welham, N. V. \& Maclagan, M. A. 2003. Vocal fatigue: current knowledge and future directions. Journal of Voice, 17, 21-30.

Wells, K. D. \& Taigen, T. L. 1986. The effect of social interactions on calling energetics in the gray treefrog (Hyla versicolor). Behavioral Ecology and Sociobiology, 19, 9-18.

Wyman, M. T., Mooring, M. S., McCowan, B., Penedo, M. C. T. \& Hart, L. A. 2008. Amplitude of bison bellows reflects male quality, physical condition and motivation. Animal Behaviour, 76, 16251639. 
Yamaguchi, A. \& Kelley, D. B. 2002. Hormonal mechanisms of acoustic communication in animals. In: Springer Handbook of Auditory Research: Acoustic Communication (Ed. by A. Simmons, A. N. Popper \& R. R. Fay), pp. 275-323. New York: Springer. 